\title{
Stature Estimation Using Postmortem Computed Tomography Scan Images of Long Limbs
}

\author{
Soon LP'*, Hasmi AH ${ }^{2}$, See KLㄴ, Mohamad Noor \\ $\mathrm{MH}^{3}$ and Feng SS ${ }^{2}$ \\ ${ }^{1}$ Department of Forensic Science, Institute of Forensic \\ Medicine Malaysia, Malaysia \\ ${ }^{2}$ Department of Forensic Pathology, Institute of Forensic \\ Medicine Malaysia, Malaysia \\ ${ }^{3}$ Department of Forensic Radiology, Kuala Lumpur \\ Hospital, Malaysia \\ *Correspondling author: Lai Poh Soon, Department of \\ Forensic Science, Institute of Forensic Medicine Malaysia, \\ Kuala Lumpur Hospital, Malaysia
}

Received: February 02, 2017; Accepted: March 03, 2017; Published: March 20, 2017

\begin{abstract}
Introduction: Estimation of stature is an important tool in developing a biological profile for human identification especially using long bones. Thus far, stature estimation had been done mostly based on the American population. Both Thai Formula [6] and Malaysia Formula [4] were currently practice applied by Forensic Anthropologists in Malaysia. Amongst the Asian population, this study had shown that Thai Formula with direct bone measurement have higher accuracy and reliability compared to the Malaysia Formula.
\end{abstract}

Methodology: A new tool is developed in this study to Formulate stature estimation by measuring via Postmortem Multislice Computed Tomography (PMCT) images on the average bilateral length measurements of 3 long bones including humerus, femur and tibia. All the postmortem cases in year 2015 involved Asian Population with known stature were included. A total sample size of 333 were selected by convenience sampling based on the archived PMCT images available and those images with fractured bones or presenting out of the PMCT framework were excluded.

Results and Discussion: Statistical analyses showed that there was a significant difference of stature between sex but not significant between population and ancestry. Statistical Package for Social Sciences (SPSS) Regression analysis proved that lower limbs have higher correlation with the stature compared with upper limbs. This study has created more reliable Formula for Malaysia population compared to Non-Malaysia Asian population. For unknown dead bodies, forensic anthropologists were recommended to use both Femur and Tibia Length and the Formula under combined category to resemble the Asian population.

Keywords: Regression Formula; Stature estimation; Postmortem computed tomography; Long limbs

\section{Introduction}

Anthropological approach is used for determination of biological profiles based on the features of the skeleton remains likewise the skull and pelvic bones for sex determination whilst the long bones for the status estimation. One of the major advantages of postmortem multislice computed tomography (PMCT) is the possibility of performing an anthropological study of the cadaver especially noninvolvement of international legal issue or criminal elements. For instance, disaster victim identification in local perspective. This avoids the necessity to prepare and deflesh bones, and the ethnic origin, stature, age and sex can be estimated using especially 3 dimensional (3D) viewers on the Digital Imaging and Communication in Medicine (DICOM) files of the PMCT images. Moreover, the anthropological preliminary reports can support the subsequent findings of primary identifiers such as Forensic Deoxyribo-Nucleic Acid (DNA), Forensic Odontology and Forensic Fingerprint. In this domain, PMCT opens a new field of research that is called virtual anthropology [1].

Several methods can be used to establish the stature of the body such as the direct measurement of the bones displayed externally or internally of the dead bodies; however this could only be estimated through the secondary identifier likewise with known biological profiles. With a continuous set of CT data, virtual sections at arbitrary angles through the volume can be calculated and the distance between two points, such as both ends of a bone, within such a plane can be measured. If the body can be laid outstretched on the examination table, its full length can be determined from the CT data in one single measurement. If this is not possible due to contractures, e.g. in burnt victims, the body stature can still be determined by adding the measured lengths of a number of skeleton segments. Finally, if the body is not complete, other anthropological methods can be applied. These are expressed as Formula which have the lengths of several of the long bones of the extremities as parameters [2].

Among all the stature predictors, the long bones of lower extremities are extensively used in stature estimation [3]. Studies have shown that femur is more reliable in estimating stature compared to skeletal elements such as metatarsal, metacarpal, calcaneum and fragmentary tibia [4]. Stature estimation may be specifically derived from each population. Specific regression for specific population is important to account for inherent population variations such as genetic and environmental factors. Furthermore, the regressions will also take into account the human internal factors such as sex and agerelated changes [4]. 
The application of CT was useful for the documentation of wholebody anatomical data on routine autopsy, virtual reconstruction of skeletal structure, objective measurements, and reassessment by repetitive analyses [3]. There were studies showing the usage of PMCT data of forensic autopsy cases of Japanese over 19 years in investigating the virtual CT morphometry of lower limb long bones, including the femur, tibia, fibula, and first metatarsus, to estimate the sex and stature (total $n=259,150$ males and 109 females). Bone mass volumes, lengths, and total CT attenuation values of bilateral femurs, tibias, and fibulas were co-related with the stature. Correlations with the stature were similar for the lengths and mass volumes of the femur, tibia, and fibula $(r=0.77-0.85)$ but were higher for the mass volume of the first metatarsus ( $\mathrm{r}=0.77$ for right and $\mathrm{r}=0.58$ for left). In addition, the ratio of the bone volume to the length of each bone showed the most significant sex-related differences (males > females with accuracy of 75.8-98.1\%). These findings illustrate the effectiveness of virtual CT morphometry of individual lower limb long bones, including volumetry, in estimating the sex and stature in identification [3].

Estimation of stature is an important step in developing a biological profile for human identification especially using femur bones that often found in the scene of death or crime scene by the police investigating officers and publics. It may provide a valuable indicator for unknown individual in a population. Thus, stature estimation had been mostly done using the regressions based on the American population; however these regressions may not be applicable to the Asian population [5].

Lists of existing Formula formerly used as references by the Forensic Anthropologists in Hospital Kuala Lumpur and Ministry of Health, Malaysia:

1. Dupertuis \& Hadden (1951) derived stature Formula from Euro Americans and African Americans populations.

2. Trotter \& Gleser (1992) initiated the Formula to estimate forensic stature based on the 3 main ancestry groups including Negroid, Caucasoid, and Mongoloid by sex.

3. Ousley (1995) provided Formula to estimate forensic stature using the data from the University of Tennessee forensic databank based on White and Black Population by sex as well.

4. Mahakkanukrauh, et al. (2011) introduced the Thai reference tables that derived from the Thai Population to be used for resembling Malaysia Population.

There were insufficient amount of studies for stature estimation in the Malaysia population but it is certainly warranted to produce regressions based on the Malaysia population. A study conducted in 2013 to analyze the relationship between stature and lower limb dimensions in the Malaysia population. The samples are 100 corpses that consist of 69 males and 31 females aged between 20 to 90 years old. The parameters measured were stature, thigh length, lower leg length, leg length, foot length, foot stature and foot breadth. Results showed that the mean values in males were significantly higher than those in females $(p<0.05)$. There were significant correlations between lower limb dimensions and stature [4]. Another study was carried out on a sample of 200 skeletons from a northern Thai population (132 males
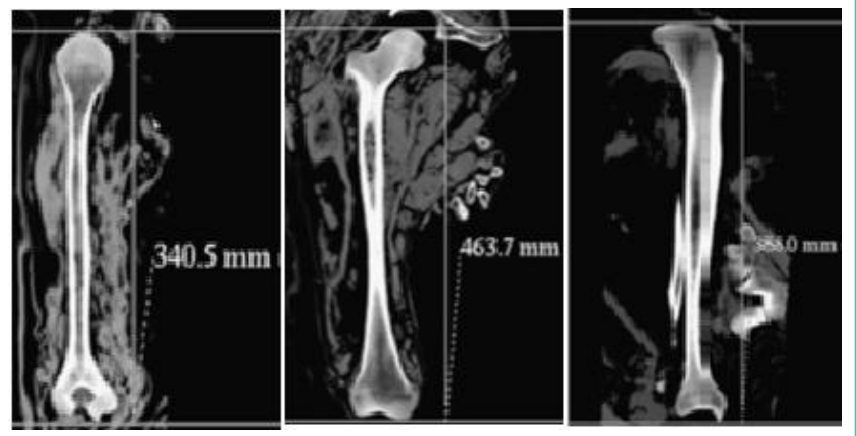

Figure 1: Left: Humerus; Middle: Femur; Right: Tibia.

and 68 females), ranging in age from 19 to 94 years. The maximum lengths of six long bones (humerus, radius, ulna, femur, tibia and fibula) were measured and the stature reconstruction Formula was generated using linear regression. The results showed that the three lower limb bones are the most accurate estimators of stature among the males [6].

The main focus of this study was to compute stature using the PMCT images of 3 long bones including humerus, femur and tibia by applying the existing Formula and subsequently compared to the actual stature. The accuracy and reliability of each Formula were compared. Occasionally, statistical analysis was conducted to formulate a new tool of stature estimation using the anthropometry data of humerus, femur and tibia length. Subsequent validation on the Formula has been conducted to confirm the effectiveness of the new tool of stature estimation.

\section{General objectives}

Compare and formulate the stature estimation by using PMCT Scan images of long bones including humerus, femur and tibia.

\section{Specific objectives}

1. Compare the accuracy and reliability of existing Formula derived from Thailand Population and Malaysia Population and practiced by Forensic Anthropologists.

2. Determine the Formula for stature estimation using PMCT images of Long Limbs such as Humerus, Femur and/or Tibia according to sex i.e. Males and Females.

3. Determine the Formula for stature estimation using PMCT images of Long Limbs i.e. Humerus, Femur and/or Tibia according to Asian Population (Malaysia versus Non-Malaysia).

4. Determine the Formula for stature estimation using PMCT images of Long Limbs such as Humerus, Femur and/or Tibia according to Malaysia ancestry i.e. Malays, Chinese and Indian.

\section{Methods}

All the postmortem cases aged 19-79 with known stature that were scanned using PMCT in 2015 included the total sample size of 333 by retrospective convenience sampling based on the archived PMCT images available in Forensic Medicine Department of Hospital Kuala Lumpur, Malaysia. This study was registered with National Medical Research Register (NMRR-16-354-29822) and has obtained clearance from local Medical Research and Ethics Committees (MREC). 
Table 1: Malaysia Formula

\begin{tabular}{|c|c|}
\hline Measurement in Males & Male Regression Equation $(\mathrm{N}=117)$ in $\mathrm{cm}$ \\
\hline Humerus (max) & $S=3.220 * \operatorname{Hum}(\max )+64.224$ \\
\hline Femur (max) & $S=2.722 *$ Fem $(\max )+45.534$ \\
\hline Tibia (max) & $\mathrm{S}=3.015 * \operatorname{Tib}(\max )+52.964$ \\
\hline Femur (max) + Tibia (max) & $\begin{array}{l}\mathrm{S}=1.675 * \text { Fem }(\max )+1.309 * \text { Tib }(\max )+ \\
42.982\end{array}$ \\
\hline Measurements in Females & Female Regression Equation $(\mathrm{N}=53)$ in $\mathrm{cm}$ \\
\hline Humerus (max) & $S=2.911 * \operatorname{Hum}(\max )+69.424$ \\
\hline Femur (max) & $S=2.778 *$ Fem $(\max )+40.602$ \\
\hline Tibia (max) & $S=2.620 * \operatorname{Tib}(\max )+63.089$ \\
\hline Femur (max) + Tibia (max) & $\begin{array}{l}S=4.007 * \text { Fem }(\max )-1.248 * \text { Tib }(\max )+ \\
33.699\end{array}$ \\
\hline
\end{tabular}

Table 2: Thai Formula.

\begin{tabular}{|l|l|}
\hline Measurement in Males & Male Regression Equation $(\mathrm{N}=69)$ in $\mathbf{~ c m}$ \\
\hline Thigh Length $(\mathrm{TL})$ & $\mathrm{S}=106.039+1.324 * \mathrm{TL}$ \\
\hline Leg Length $(\mathrm{LL})$ & $\mathrm{S}=95.102+1.677 * \mathrm{LL}$ \\
\hline Measurements in Females & Female Regression Equation $(\mathrm{N}=\mathbf{3 1})$ in cm \\
\hline Thigh Length $(\mathrm{TL})$ & $\mathrm{S}=1212.256+0.773 * \mathrm{TL}$ \\
\hline Leg Length $(\mathrm{LL})$ & $\mathrm{S}=98.158+1.426 * \mathrm{LL}$ \\
\hline
\end{tabular}

Note: TL: Midpoint of inguinal line to Inferior border of patellar; LL: Knee joint to lateral malleolus.

Exclusion criteria's were all the fractured bones or presenting out of the PMCT framework to eliminate the bone defects factor and dead bodies aged below 18 years also were excluded to avoid any age-dependent developmental factor. Throughout this retrospective study, the distance between two points, i.e. both ends of the long bone within a plane was measured following anatomical position. Figure 1 showed the measurements of dead bodies' humerus length $(\mathrm{H})$, femur length $(\mathrm{F})$ and tibia length $(\mathrm{T})$ in reformatted CT images through OsiriX using its measuring scales. The scales are corrected to 0.1 millimeter, however it was rounded up to .1 centimeter $(\mathrm{cm})$ to equalize with the stature measurement of $0.1 \mathrm{~cm}$ as well as the stature measuring scale during postmortem examination following the anatomical position on the autopsy table.

All the 3 long bones were measured bilaterally and the averages of the both sides were computed for further analysis. Average length of each 3 long bones was computed using the Malaysia Formula (Table 1) and Thai Formula (Table 2) as shown below. The resulted computation was compared to the actual stature measured during postmortem examination.

By using the overall population, the comparison was done by SPSS Paired-T Test between the computed stature using existing Formula and the actual stature. This test was also used to determine whether there were any significant differences among each of computed stature within and between 2 types of Formula used. Then the degree of the differences were determined by analysis of the deviation of the computed stature from the actual stature i.e. $\pm 1, \pm 2, \pm 3, \pm 5, \pm 9$ and exceeding $\pm 10 \mathrm{~cm}$. The percentage of the deviation within the certain modulus absolute values from the actual stature was studied to determine the accuracy of the Formula. These analyses were then grouped by sex, population and ancestry to detect any differences of accuracy across the groups.
Table 3: Paired-T Test between Computed Stature and Actual Stature.

\begin{tabular}{|c|c|c|c|c|}
\hline \multicolumn{5}{|c|}{ Paired Samples Test } \\
\hline Pair 1 & Height - Thai_H & 14.524 & 279 & .000 \\
\hline Pair 2 & Height - Thai_F & -3.372 & 312 & .001 \\
\hline Pair 3 & Height - Thai_T & 14.558 & 293 & .000 \\
\hline Pair 4 & Height - Thai_F+T & 5.455 & 283 & .000 \\
\hline Pair 5 & Height - Msia_TL & 3.586 & 312 & .000 \\
\hline Pair 6 & Height - Msia_LL & 32.725 & 293 & .000 \\
\hline Pair 7 & Thai_H - Thai_F & -21.695 & 271 & .000 \\
\hline Pair 8 & Thai_H - Thai_T & -2.257 & 257 & .025 \\
\hline Pair 9 & Thai_H - Thai_F+T & -12.205 & 250 & .000 \\
\hline Pair 10 & Thai_F - Thai_T & 20.831 & 283 & .000 \\
\hline Pair 11 & Thai_F - Thai_F+T & 17.848 & 283 & .000 \\
\hline Pair 12 & Thai_T - Thai_F+T & -16.701 & 283 & .000 \\
\hline Pair 13 & Msia_TL - Msia_LL & 59.490 & 283 & .000 \\
\hline Pair 14 & Thai_F - Msia_TL & 9.919 & 312 & .000 \\
\hline Pair 15 & Thai_T - Msia_LL & 29.496 & 293 & .000 \\
\hline & & & & \\
\hline
\end{tabular}

Two types of Formula based on sex were used; four Thai Formula and two Malaysia Formula. Each type of Formula would create a range of stature with minimum and maximum values. Subsequently, the actual stature was compared to the range created within deviation $\pm 1 \mathrm{~cm}$. Those cases without creating a range were excluded from the analysis. The percentage of actual stature within the range was calculated. These analyses were again grouped by sex, population and ancestry to detect any differences of reliability across the groups.

By using the overall population in the study, SPSS Regression analysis was used to determine the correlation of the lengths of Humerus, Femur and Tibia with the actual stature and a new tool of Formula were then created. This again was analyzed by sex, population and ancestry to Formulate according to respective groups. From all the Formula generated, we would recommend best-fitted Formula to be used by the other researchers and for further study or validation. The measurement was conducted by only one observer to avoid inter-observer error. Intra-observer error could be detected using outlier value from 3 standard deviations.

\section{Results and Discussion}

The analysis of the demographic data showed that average age of selected samples was 60 . The ratio of Males to Females was at 4:1 in which truly reflecting the proportional rate of postmortem cases by sex in Hospital Kuala Lumpur. Malaysia population is $60 \%$ of the total samples taken. Among the Non-Malaysia Asian population, the majority Indonesian (30\%), Bangladeshi (20\%), India citizens (17\%), Myanmar citizens (17\%) and miscellaneous (16\%). The significance and confidence level p-value of the SPSS analysis throughout the study was $\mathrm{p}<0.05$. Accuracy rates were always expected to be at least $85 \%$ and above in the forensic application and standard.

The Paired-T Test between the computed stature using existing Formula and the actual stature (Pair 1-6) showed significant differences with $\mathrm{p}<0.05$. There were also significant difference with 
Table 4: Accuracy between Existing Formula.

\begin{tabular}{|c|c|c|c|c|c|c|}
\hline \multicolumn{7}{|c|}{ Overall } \\
\hline \multirow{2}{*}{ I cm I } & \multirow{2}{*}{ Humerus } & \multicolumn{2}{|c|}{ Thai Formula } & \multirow{2}{*}{$F+T$} & \multicolumn{2}{|c|}{ Msia Formula } \\
\hline & & Femur & Tibia & & $F(T L)$ & $\mathrm{T}(\mathrm{LL})$ \\
\hline 0 & 30 & 46 & 23 & 50 & 55 & 7 \\
\hline 1 & 20 & 39 & 31 & 52 & 53 & 9 \\
\hline 2 & 27 & 56 & 31 & 38 & 41 & 9 \\
\hline 3 & 26 & 51 & 32 & 33 & 35 & 14 \\
\hline $4 \leq 6$ & 23 & 42 & 24 & 22 & 28 & 8 \\
\hline $6 \leq 9$ & 94 & 63 & 113 & 72 & 82 & 112 \\
\hline$\geq 10$ & 66 & 22 & 44 & 19 & 25 & 139 \\
\hline Total & 286 & 319 & 298 & 286 & 319 & 298 \\
\hline I cm I & Humerus & Femur & Tibia & $\mathrm{F}+\mathrm{T}$ & $F(T L)$ & $\mathrm{T}(\mathrm{LL})$ \\
\hline 0 & $10 \%$ & $14 \%$ & $8 \%$ & $17 \%$ & $17 \%$ & $2 \%$ \\
\hline$\leq 1$ & $17 \%$ & $27 \%$ & $18 \%$ & $36 \%$ & $34 \%$ & $5 \%$ \\
\hline$\leq 2$ & $27 \%$ & $44 \%$ & $29 \%$ & $49 \%$ & $47 \%$ & $8 \%$ \\
\hline$\leq 3$ & $36 \%$ & $60 \%$ & $39 \%$ & $60 \%$ & $58 \%$ & $13 \%$ \\
\hline$\leq 5$ & $44 \%$ & $73 \%$ & $47 \%$ & $68 \%$ & $66 \%$ & $16 \%$ \\
\hline$\leq 9$ & $77 \%$ & $93 \%$ & $85 \%$ & $93 \%$ & $92 \%$ & $53 \%$ \\
\hline$\geq 10$ & $100 \%$ & $100 \%$ & $100 \%$ & $100 \%$ & $100 \%$ & $100 \%$ \\
\hline
\end{tabular}

$\mathrm{p}<0.05$ among each of computed stature for both within (Pair 7 -13) and between (Pair 14 - 15) 2 types of Formula used. Analysis of the deviation of the computed stature from the actual stature i.e. i.e. \pm 1 , $\pm 2, \pm 3, \pm 5, \pm 9$ and exceeding $\pm 10 \mathrm{~cm}$ were shown in the Table 3 . The higher the percentage of the deviation within modulus absolute values from the actual stature, the higher the accuracy of the used Formula. These analyses were done to detect any differences of accuracy across the sex, population and ancestry.

Table 4 comprising the overall population shown that Thai Formula and Malaysia Formula using Femur length alone were more accurate than the other long bone measurements in estimating stature. In terms of accuracy, there were no significant differences by sex across population and ancestry within Malaysia. However, Malaysia Indian had exceptionally shown that the use of Tibia length via Thai Formula was more accurate compared to other ancestry and it was also recommended to use the combination of Femur length and Tibia length for stature estimation due to its even higher percentage of accuracy. For Non-Malaysia Asian Population, the results shown that combination of Femur length and Tibia length of Thai Formula were more accurate than Tibia length alone. Generally, Thai Formula had a higher percentage of accuracy than the Malaysia Formula within every single category of analyses especially involved Femur length measurements because the computed stature did not deviated much from the actual stature.

Based on the analyses shown in Table 5, Thai Formula (67\%) were generally more reliable than Malaysia Formula (59\%) especially in Male. Both maximum and minimum values of computed stature via Thai Formula or Malaysia Formula using long bone measurements were taken into consideration. Both types of the Formula were more reliable to be used for Non-Malaysia Asian Population compare to the local people as higher percentage of actual stature stayed within the range of computed stature. There were significant differences of reliability percentage amongst the ancestry in Malaysia. Both Formulas were surprisingly more reliable when used within Malaysia Indian Population, followed by Malay and then Chinese. However, Thai Formula was preferred with higher reliability percentage than Malaysia Formula for Malaysia Population. This might have been due to origin of Malaysia Formula was generated using slightly different methodology whereby thigh length and leg length were measured compared to origin of Thai Formula that were estimated using direct measurement of bone samples.

From the results shown in Table 4 and Table 5, we had concluded that Thai Formula had higher percentage of accuracy and reliability compared to Malaysia Formula especially when using Femur Length as the main anthropometry for the stature estimation. Femur is less influenced by nutritional and other environmental stresses than the more distal bones of the limbs i.e. humerus [4]. The femur in intact state showed the highest correlation with stature, and yielded the best accuracy probably because it contributes to the living stature the most.

Through SPSS Regression analysis, the correlation of the Humerus length, Femur length and Tibia length with the actual stature or height could be determined. A new tool of Formula was created and analyzed by sex, population and ancestry. Table 6 showed the descriptive statistics for the bone length and height of the subjects in this study. Statistical analyses showed that there was a significant difference between sex but not significant between population and ancestry. Males significantly possessed longer bone length and stature compared to females. In term of average bone length and stature, Malaysia population was relatively higher than Non-Malaysia Asian population. Among the ancestry in Malaysia, Indian ranked first in skeletal measurements and stature followed by Malay and then Chinese.

The higher the $r$-squared value $(>0.500)$, the lower the standard error of the estimate and the stronger the regression of the regression Formula generated. SPSS Regression analysis showed that lower

Table 5: Reliability between Existing Formula

\begin{tabular}{|c|c|c|c|c|c|c|c|}
\hline \multirow{2}{*}{ Within Range \pm 1} & \multicolumn{3}{|c|}{ Thai Formula } & \multirow{2}{*}{ Within Range \pm 1} & \multicolumn{3}{|c|}{ Malaysia Formula } \\
\hline & Male & Female & Total & & Male & Female & Total \\
\hline Yes & 193 & 23 & 216 & Yes & 147 & 22 & 169 \\
\hline No & 87 & 18 & 105 & No & 101 & 16 & 117 \\
\hline Total & 280 & 41 & 321 & Total & 248 & 38 & 286 \\
\hline \%Reliable & $69 \%$ & $56 \%$ & $67 \%$ & \%Reliable & $59 \%$ & $58 \%$ & $59 \%$ \\
\hline
\end{tabular}

Note: Yes = within range of the maximum and minimum values of the 4 Thai Formula or 2 Malaysia Formula.

$\mathrm{No}=$ out from range of the maximum and minimum values of the 4 Thai Formula or 2 Malaysia Formula. 
Table 6: Descriptive Statistics.

\begin{tabular}{|c|c|c|c|c|c|}
\hline Skeletal Measurement & $\mathbf{N}$ & Minimum & Maximum & Mean & SD \\
\hline \multicolumn{6}{|l|}{ Males } \\
\hline Humerus & 247 & 24.4 & 37.4 & 29.46 & 1.79 \\
\hline Femur & 275 & 33.3 & 52.1 & 44.03 & 2.6 \\
\hline Tibia & 254 & 29.6 & 41.9 & 35.43 & 2.25 \\
\hline Actual Height & 283 & 146 & 191 & 165.15 & 7.29 \\
\hline \multicolumn{6}{|l|}{ Females } \\
\hline Humerus & 32 & 22.4 & 29.4 & 26.15 & 1.62 \\
\hline Femur & 38 & 35.9 & 44.7 & 40.18 & 1.98 \\
\hline Tibia & 40 & 27.5 & 38.6 & 32.67 & 1.97 \\
\hline Actual Height & 41 & 140 & 171 & 153.84 & 6.54 \\
\hline \multicolumn{6}{|l|}{ Combined } \\
\hline Humerus & 279 & 22.4 & 37.4 & 29.15 & 1.97 \\
\hline Femur & 313 & 33.3 & 52.1 & 43.56 & 2.83 \\
\hline Tibia & 294 & 27.5 & 41.9 & 35.06 & 2.41 \\
\hline Actual Height & 324 & 140 & 191 & 163.72 & 8.12 \\
\hline \multicolumn{6}{|l|}{ Malay } \\
\hline Humerus & 85 & 24.4 & 33.7 & 29.44 & 1.8 \\
\hline Femur & 92 & 38.3 & 49.6 & 43.87 & 2.27 \\
\hline Tibia & 85 & 30.8 & 40.2 & 35.36 & 1.97 \\
\hline Actual Height & 96 & 149 & 184 & 165.68 & 7.22 \\
\hline \multicolumn{6}{|l|}{ Chinese } \\
\hline Humerus & 48 & 22.4 & 32.5 & 28.47 & 1.98 \\
\hline Femur & 57 & 35.9 & 50.3 & 42.68 & 2.81 \\
\hline Tibia & 55 & 27.5 & 37.8 & 33.88 & 2.09 \\
\hline Actual Height & 61 & 140 & 182 & 162.58 & 8.03 \\
\hline \multicolumn{6}{|l|}{ Indian } \\
\hline Humerus & 44 & 25 & 32.9 & 30.09 & 1.72 \\
\hline Femur & 52 & 40 & 52.1 & 45.72 & 2.44 \\
\hline Tibia & 56 & 29.6 & 41.9 & 36.78 & 2.6 \\
\hline Actual Height & 54 & 148 & 191 & 167.49 & 8.67 \\
\hline \multicolumn{6}{|l|}{ Malaysian } \\
\hline Humerus & 186 & 22.4 & 33.9 & 29.36 & 1.93 \\
\hline Femur & 211 & 35.9 & 52.1 & 44.11 & 2.76 \\
\hline Tibia & 193 & 27.5 & 41.9 & 35.33 & 2.48 \\
\hline Actual Height & 221 & 140 & 191 & 165.24 & 8.03 \\
\hline \multicolumn{6}{|l|}{ Non-Malaysian (Asian) } \\
\hline Humerus & 91 & 22.9 & 37.4 & 28.71 & 1.99 \\
\hline Femur & 100 & 36.8 & 49.2 & 42.49 & 2.48 \\
\hline Tibia & 99 & 30.2 & 39.9 & 34.44 & 2.09 \\
\hline Actual Height & 101 & 142 & 183 & 160.29 & 7.31 \\
\hline
\end{tabular}

Note: All measurements were taken in centimeter.

limbs had higher correlation with the stature $\left(\mathrm{r}^{2}<0.500\right)$ in all occasion compared with upper limb i.e. humerus. Generally, Formula using Femur Length in most of the cases were stronger than the combination of Femur length and Tibia length except in Chinese and
Table 7: Regression Formula.

\begin{tabular}{|c|c|c|c|c|}
\hline Skeletal Measurement & Formula & $r^{2}$ & SEE & rms \\
\hline \multicolumn{5}{|l|}{ Males } \\
\hline Humerus $(\mathrm{H})$ & $1.975 * H+106.358$ & 0.255 & 6.056 & 36.677 \\
\hline Femur $(F)$ & $2.062 * F+74.494$ & 0.543 & 4.933 & 24.332 \\
\hline Tibia (T) & $2.039 * T+92.078$ & 0.466 & 4.928 & 24.285 \\
\hline Femur + Tibia $(F+T)$ & $\begin{array}{l}1.186 * \mathrm{~F}+1.093 * T+ \\
73.804\end{array}$ & 0.555 & 4.488 & 20.145 \\
\hline \multicolumn{5}{|l|}{ Females } \\
\hline Humerus $(\mathrm{H})$ & $1.714 * \mathrm{H}+107.406$ & 0.194 & 5.68 & 32.265 \\
\hline Femur $(F)$ & 1.570 *F+ 91.196 & 0.247 & 5.511 & 30.369 \\
\hline Tibia (T) & $1.716 * T+97.815$ & 0.261 & 5.764 & 33.224 \\
\hline Femur + Tibia $(F+T)$ & $\begin{array}{l}0.977 * F+0.706 * T+ \\
91.886\end{array}$ & 0.262 & 5.613 & 31.51 \\
\hline \multicolumn{5}{|l|}{ Combined } \\
\hline Humerus $(\mathrm{H})$ & 2.370 *H +94.140 & 0.359 & 6.248 & 39.042 \\
\hline Femur (F) & $2.193 * F+68.383$ & 0.598 & 5.088 & 25.891 \\
\hline Tibia (T) & $2.280 * T+82.924$ & 0.522 & 5.261 & 27.673 \\
\hline Femur + Tibia $(F+T)$ & $\begin{array}{l}1.325 * F+1.081 * T+ \\
67.753\end{array}$ & 0.602 & 4.731 & 22.383 \\
\hline \multicolumn{5}{|l|}{ Malay } \\
\hline Humerus $(\mathrm{H})$ & 2.684 * $\mathrm{H}+86.252$ & 0.45 & 5.371 & 28.843 \\
\hline Femur (F) & $2.657^{\star} F+49.281$ & 0.700 & 3.976 & 15.812 \\
\hline Tibia (T) & $2.679 * T+70.022$ & 0.591 & 4.41 & 19.45 \\
\hline Femur + Tibia $(\mathrm{F}+\mathrm{T})$ & $1.994^{*} F+0.776 * T+50.538$ & 0.687 & 3.884 & 15.084 \\
\hline \multicolumn{5}{|l|}{ Chinese } \\
\hline Humerus $(\mathrm{H})$ & $2.538 * \mathrm{H}+89.095$ & 0.444 & 5.668 & 32.129 \\
\hline Femur (F) & $2.056^{*} \mathrm{~F}+75.204$ & 0.567 & 5.104 & 26.046 \\
\hline Tibia (T) & $2.555 * T+75.677$ & 0.459 & 5.830 & 33.991 \\
\hline Femur + Tibia $(F+T)$ & $1.490 * \mathrm{~F}+0.756 * \mathrm{~T}+73.598$ & 0.508 & 5.292 & 28.000 \\
\hline \multicolumn{5}{|l|}{ Indian } \\
\hline Humerus $(\mathrm{H})$ & $2.511 * \mathrm{H}+91.063$ & 0.32 & 3.363 & 40.49 \\
\hline Femur (F) & $2.776 * F+41.298$ & 0.691 & 4.568 & 20.862 \\
\hline Tibia (T) & $2.178 * \mathrm{~T}+86.009$ & 0.533 & 5.362 & 28.755 \\
\hline Femur + Tibia $(\mathrm{F}+\mathrm{T})$ & $1.898 * \mathrm{~F}+0.737 * \mathrm{~T}+53.398$ & 0.651 & 4.328 & 18.73 \\
\hline \multicolumn{5}{|l|}{ Malaysian } \\
\hline Humerus $(\mathrm{H})$ & 2.494 * $\mathrm{H}+91.356$ & 0.396 & 5.971 & 35.655 \\
\hline Femur $(F)$ & $2.217 * F+67.836$ & 0.614 & 4.857 & 23.592 \\
\hline Tibia (T) & $2.197 * T+86.682$ & 0.522 & 5.208 & 27.119 \\
\hline Femur + Tibia $(F+T)$ & $\begin{array}{l}1.596 * \mathrm{~F}+0.661 \text { * } T+ \\
71.345\end{array}$ & 0.595 & 4.641 & 21.541 \\
\hline \multicolumn{5}{|l|}{$\begin{array}{l}\text { Non-Malaysian } \\
\text { (Asian) }\end{array}$} \\
\hline Humerus (H) & $1.883 * H+106.382$ & 0.257 & 6.399 & 40.944 \\
\hline Femur $(F)$ & 1.896 * $F+80.043$ & 0.462 & 5.406 & 29.227 \\
\hline Tibia (T) & $2.220 * T+83.530$ & 0.482 & 5.075 & 25.752 \\
\hline Femur + Tibia $(F+T)$ & $\begin{array}{l}0.991 * F+1.521 * T+ \\
65.753\end{array}$ & 0.568 & 4.669 & 21.802 \\
\hline
\end{tabular}

Note: $r$-Squared value $\left(r^{2}\right)$, standard error of the estimate (SEE), residual mean square (rms), $r^{2}>0.500$ indicated strong regression Formula.

Female. However, forensic anthropologist was recommended to use the combination of Femur length and Tibia length for unknown dead 
bodies by referring to combined category. This study had created more reliable Formula for Malaysia population compared to NonMalaysia Asian population. Unfortunately, the Formula under female category were less correlated to be used for stature estimation due to $r^{2}<0.300$ in which much lower than the other categories as shown in Table 7 . Hence, a validation test should be conducted to determine the accuracy and reliability of the new tool created.

A blind validation on the Formula generated from this research, as indicated in Table 7, was conducted using total of selected 28 random cases that were different from the primary sample of 333 cases. Results showed that Combined Formula (61\%) are more reliable than Formula by sex, however less reliable than Formula by population and ancestry among Malaysia. For instance if the sex, nationality and/or ancestry were known, the reliability of the Formula will be increased. In terms of accuracy within deviation of $\pm 3 \mathrm{~cm}$, Formula generated in this research were generally more than $70 \%$ accurate for each category that using the combination of femur length and tibia length up to $100 \%$ accurate except the Formula for Malaysia females that had about only $60 \%$ accuracy.

There were some limitation on this research, convenience sampling was chosen as the sampling technique based on retrospective available PMCT images throughout year 2015 and noticed that we were lacking of female subjects due to common mortality ratio subjected to postmortem examination. Another problem encountered was that the dead bodies were sometimes not properly aligned within the framework of the PMCT and contributing to lots of missing values. Cases with very mild fractured bones would still be included; however, other bones without fracture would be taken into consideration for measurements. The OsiriX programme itself was only equipped with $2 \mathrm{D}$ viewer and hence rotation of the images was not possible and control the standardized orientation of the bones for measurement purpose. We have to make assumption that all the actual stature stated by medical officers and forensic pathologists were all measured following standard protocol and reflecting true value of the height of the subjects without any doubt. Intra-observer and inter-observer errors were hardly be determined.

\section{Conclusion}

In summary, this research had shown that Thai Formula have higher percentage of accuracy and reliability compared to Malaysia Formula especially when using the Femur Length as the main estimator in computing the stature. This had proved that the Thai Formula could generate a computed stature that comparably close to the actual stature with smaller deviation. The range of computed stature formed using the different bone length via Thai Formula was also more reliable in reflecting the actual stature to be in that range of minimum and maximum values.

Forensic anthropologist was recommended to use the combination of Femur and Tibia Length for unknown dead bodies. If the skeletal remains were identified as Malaysia and with known ancestry especially Malay Male population, it was highly proposed to use the Formula generated in this study. Again due to the convenient sampling method by using only the postmortem cases at Hospital Kuala Lumpur, the new tool of generated Formula might not resemble the whole Malaysia population. Hence, we would suggest to other researchers to conduct a validation within their own population to determine whether the Formula resembling samples taken in this study comparable to their study.

\section{References}

1. Dedouit F, Telmon N, Costagliola R, Otal P, Florence LL, Joffre F, et al. New identification possibilities with postmortem multislice computed tomography. Int J Legal Med. 2007; 121: 507-510.

2. Sidler $M$, Jackowski $C$, Dirnhofer $R$, Vock $P$, Thali $M$. Use of multislice computed tomography in disaster victim identification--advantages and limitations. Forensic Sci Int. 2007; 169: 118-128.

3. Hishmat AM, Michiue T, Sogawa N, Oritani S, Ishikawa T, Fawzy IA, et al. Virtual CT morphometry of lower limb long bones for estimation of the sex and stature using postmortem Japanese adult data in forensic identification. Int $\mathrm{J}$ Legal Med. 2015; 129: 1173-1182.

4. FM Nor, Abdullah N, Mustapa AM, Wen LQ, Faisal NA, Ahmad Nazari DAA. 2013. Stature Estimation Based On Lower Limb Dimensions in the Malaysia Population. Int J Med Health BioMed Bio Engin Phar Engin. 2013; 7.

5. Auyeung TW, Lee JS, Kwok T, Leung J, Leung PC, Woo J. Estimation of stature by measuring fibula and ulna bone length in 2443 older adults. J Nutr Health Aging. 2009; 13: 931-936.

6. Mahakkanukrauh P, Khanpetch P, Prasitwattanseree S, Vichairat K, Troy Case D. Stature estimation from long bone lengths in a Thai population. Forensic Sci Int. 2011; 210: 279.
Austin J Forensic Sci Criminol - Volume 4 Issue 1 - 2017 ISSN : 2380-0801 | www.austinpublishinggroup.com Soon et al. ( ) All rights are reserved
Citation: Soon LP, Hasmi AH, See KL, Mohamad Noor MH and Feng SS. Stature Estimation Using Postmortem Computed Tomography Scan Images of Long Limbs. Austin J Forensic Sci Criminol. 2017; 4(1): 1059. 